\title{
O Tribunal Penal Internacional: de uma cultura de impunidade para uma cultura de responsabilidade
}

\author{
ENRIQUE RICARDO LEWANDOWSKI
}

\section{O Tratado de Roma}

$\mathrm{O}$ TRATAdo De Roma, que prevê a criação do Tribunal Penal Internacional vinculado à Organização das Nações Unidas (ONU), foi aprovado em 17 de julho de 1998 por uma maioria de 120 votos a favor, 7 em contrário (da China, Estados Unidos, Filipinas, Índia, Israel, Sri Lanka e Turquia) e 21 abstenções. No dia 11 de abril de 2002, o Tratado alcançou 66 ratificações, ultrapassando o número de adesões exigido para sua entrada em vigor. O Brasil assinou o pacto em 12 de fevereiro de 2000, ratificando-o em 12 de junho de 2002, depois de aprovado pelo Congresso Nacional, tornando-se o $69^{\circ}$ Estado a reconhecer a jurisdição do TPI (1).

A nova Corte, sediada em Haia, na Holanda, terá competência para julgar os chamados crimes contra a humanidade, assim como os crimes de guerra, de genocídio e de agressão. Sua criação constitui um avanço importante, pois esta é a primeira vez na história das relações entre Estados que se consegue obter o necessário consenso para levar a julgamento, por uma corte internacional permanente, políticos, chefes militares e mesmo pessoas comuns pela prática de delitos da mais alta gravidade, que até agora, salvo raras exceções, têm ficado impunes, especialmente em razão do princípio da soberania.

\section{Soberania e jurisdição doméstica}

Por volta do fim da Idade Média, que os historiadores costumam fixar no ano de 1453, data da tomada de Constantinopla pelos turcos otomanos, surgiu na Europa o Estado Moderno. Essa nova entidade diferia das estruturas de poder que a antecederam pelo exercício da soberania, que se desenvolveu no momento em que certos reis e príncipes, com o apoio da burguesia e de parte da aristocracia feudal, subtraíram as competências normativas dos vários centros de poder existentes na Idade Média, eliminando, assim, a poliarquia que caracterizava a ordem política medieval. O Estado passou a constituir então a summa potestas relativamente aos demais poderes que atuavam em seu território.

Depois de adquirir a supremacia no âmbito interno, o Estado livrou-se também das limitações que os governantes medievais sofriam na condução de suas relações exteriores, representadas pelas ingerências da Igreja Católica e do 
Sacro Império Romano Germânico, que pretendiam deter a hegemonia decisória nos domínios espiritual e político, respectivamente. A soberania, pois, como manifestação do poder do Estado no plano externo, passou a ser sinônimo de independência.

A soberania estatal, assim considerada, levou à introdução da denominada cláusula de jurisdição doméstica nos atos constitutivos das organizações interna-

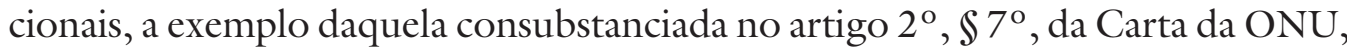
que consagra o princípio da não-intervenção nos assuntos internos de seus membros (2), cuja observância tem impedido uma repressão mais eficaz aos atentados contra os direitos humanos cometidos por Estados ou alguém em seu nome.

\section{Irresponsabilidade dos governantes}

Até o término da Segunda Guerra Mundial, muito pouco se fez, no plano internacional, por absoluta falta de meios legais e institucionais, para coibir genocídios, massacres, assassinatos, torturas, mutilações e outras ofensas graves aos direitos humanos praticados em grande escala, sobretudo porque prevalecia o entendimento de que os governantes, no exercício da soberania estatal, eram juridicamente irresponsáveis por seus atos.

A idéia da inimputabilidade dos governantes, embora profundamente arraigada na cultura política desde a mais remota antiguidade, somente tomou forma doutrinária com Maquiavel, em 1513, segundo o qual "um príncipe, e especialmente um príncipe novo, não pode observar todas as coisas a que são obrigados os homens considerados bons, sendo freqüentemente forçado, para manter o governo, a agir contra a caridade, a fé, a humanidade e a religião" (3).

Essa tese ganhou contornos jurídicos na obra de Bodin intitulada Os seis livros da República, datada de 1576, que definia a soberania como um poder "absoluto e perpétuo do Estado" (4). Hobbes, por sua vez, levou a extremos a teoria do poder ilimitado dos reis, sustentando, em seu Leviatãa, editado em 1651, que os homens alienaram seus direitos naturais ao soberano em troca da segurança, posto que antes da constituição do Estado viviam numa "guerra de todos contra todos" (5). Tais idéias foram ainda aperfeiçoadas pelos defensores do direito divino dos reis, dentre os quais Bossuet, que acreditavam que os governantes eram representantes de Deus na Terra e, como tal, só a Ele deviam satisfação por seus atos (6).

A partir daí, a tese da irresponsabilidade dos governantes ganhou maior sofisticação com a raison d'Etat de Richelieu e a Realpolitik de Bismarck, que davam como legítima qualquer ação praticada em nome dos superiores interesses do Estado (7). E tal doutrina durante séculos não sofreu maiores abalos, em que pesem as barbaridades cada vez maiores praticadas nas guerras declaradas e não-declaradas que eclodiram desde os albores da Idade Moderna até os dias atuais. 


\section{De Nüremberg a Haia}

A tese da inimputabilidade dos governantes somente começou a modificar-se depois da Primeira Guerra Mundial, em virtude da destruição sem precedentes causada pelo emprego das novas armas de extermínio em massa e diante das indizíveis atrocidades praticadas pelas potências beligerantes nos campos de batalha e fora deles, que levaram à morte mais de 15 milhões de pessoas (8). Isso fora o massacre de cerca de um milhão de armênios, pelos turcos, em 1915.

Embora até essa época jamais um governante, chefe militar ou mesmo simples soldado tenha sido responsabilizado por crimes cometidos em ações bélicas, as potências vencedores, capitaneadas por Lloyd George e David Clemenceau, respectivamente chefes de governo da Grã-Bretanha e da França, manifestaram a intenção de punir aqueles que praticaram atos ofensivos às leis da humanidade $\mathrm{e}$ às normas de conduta civilizada durante a guerra. O Tratado de Paz de Versalhes, de 1919, até chegou a incluir um dispositivo nesse sentido, pois os aliados pretendiam levar o imperador Guilherme II da Alemanha a julgamento (9). Mas a punição dos vencidos, como se sabe, resumiu-se a uma vultosa indenização, jamais paga integralmente (10).

Alguns esforços foram feitos nos anos seguintes à celebração do acordo de paz para a criação de uma corte criminal internacional, mas esbarraram na resistência da comunidade diplomática, ainda aferrada à idéia da irresponsabilidade dos agentes estatais. Esse apego a uma doutrina ultrapassada pela realidade dos fatos custou muito caro à humanidade. Com efeito, as atrocidades cometidas na Segunda Guerra Mundial ultrapassaram os limites da barbárie, bastando assinalar que nela pereceram mais de 55 milhões de pessoas (11).

Nesse contexto de horror, os vencedores empreenderam o primeiro passo concreto no sentido de punir aquilo que se passou a considerar crime contra a humanidade, conceito amplo que compreendia o assassinato em massa, a escravidão, o genocídio e outros delitos correlatos, bem como o crime contra a paz, identificado com a guerra de agressão, considerados contrários ao direito internacional (12). Para tanto, foram instituídos os tribunais de Nüremberg e de Tóquio para julgar dirigentes políticos e militares das potências derrotadas, que rejeitaram as escusas levantadas pelos acusados para escapar à punição, como o cumprimento de ordens superiores, a prática de atos de soberania e a tomada de medidas ditadas pela necessidade militar.

Essa experiência, todavia, não teve o condão de intimidar os criminosos de guerra, que continuaram a agir livremente nos inúmeros conflitos que tiveram lugar na segunda metade do século XX. A situação de absoluta impunidade perdurou até recentemente, quando a comunidade internacional decidiu intervir na ex-Iugoslávia, onde uma luta fratricida lançou sérvios contra croatas e outras etnias, e em Ruanda, em cujo território extremistas hutus massacraram os rivais da nação tutsi. Foram então criados dois tribunais ad hoc para aquelas áreas, em 1993 e 1994, respectivamente, para fazer cessar e punir os gravíssimos abusos 


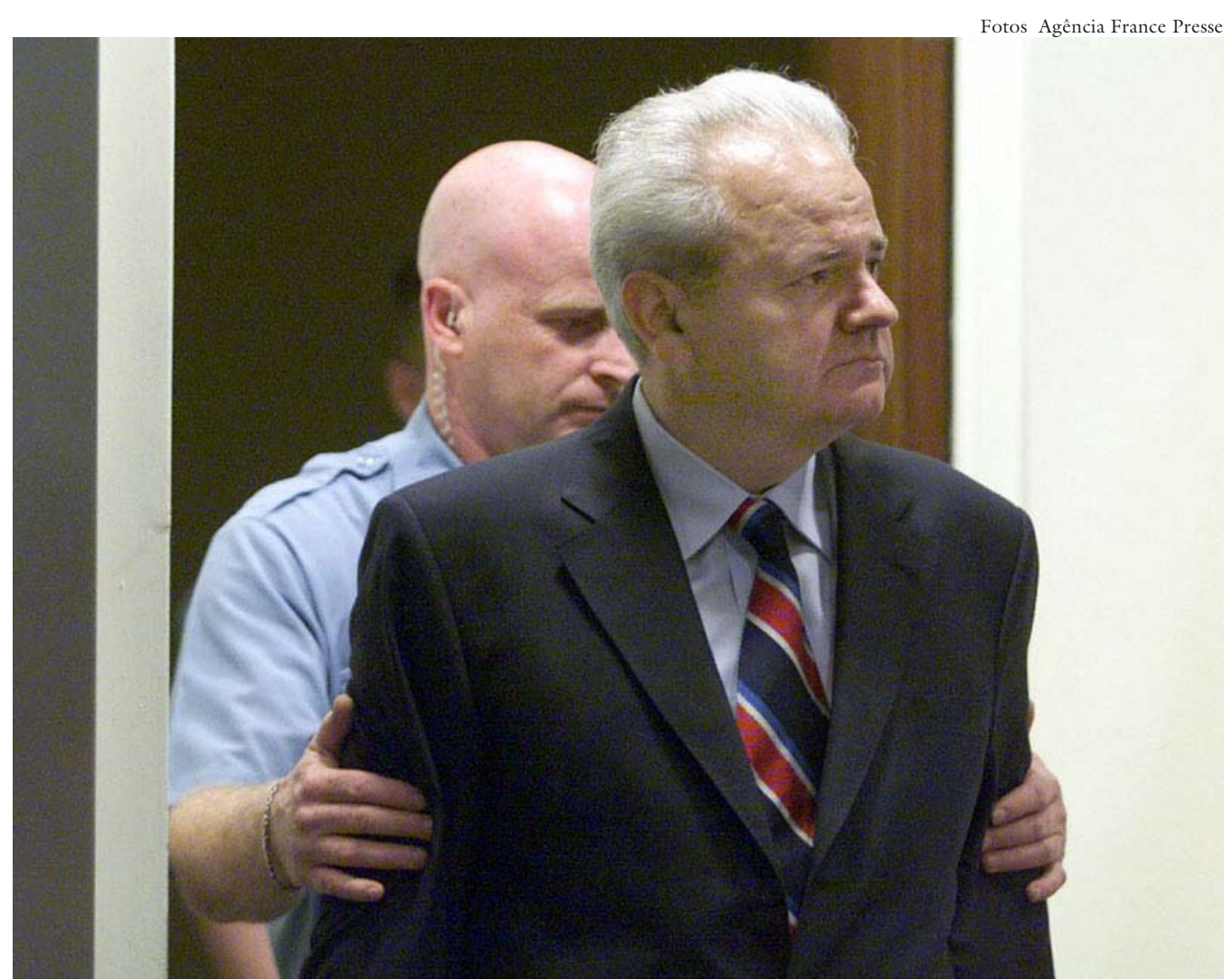

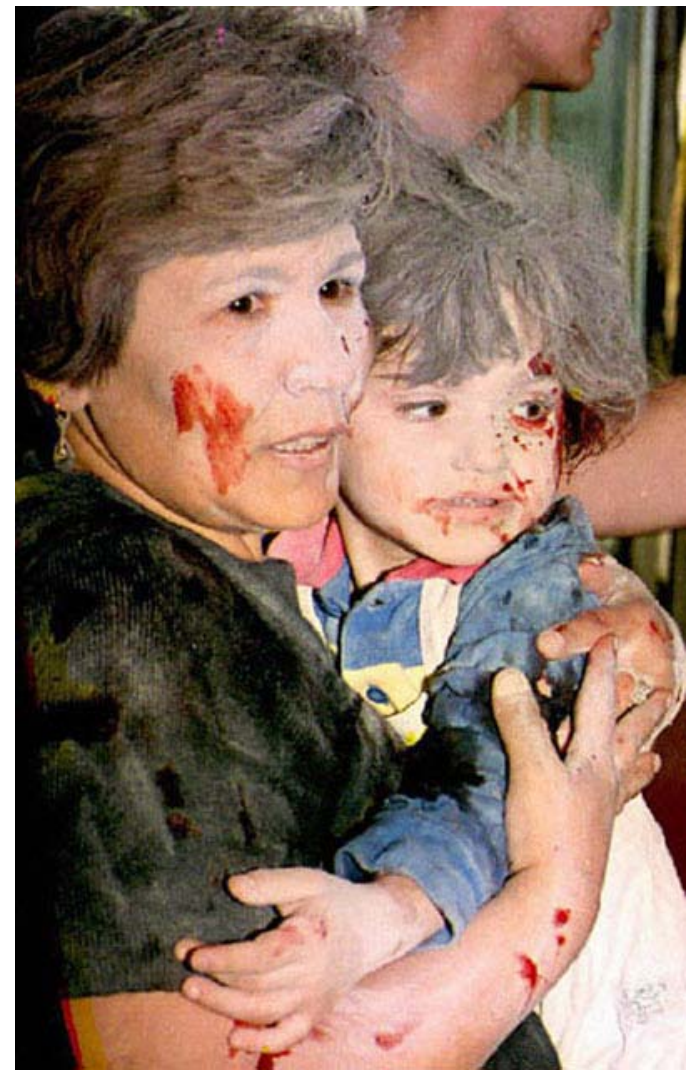

cometidos em ambas as contendas. A atuação dessas cortes acabou produzindo um bônus adicional, sob a forma de um importante precedente, qual seja, o julgamento de pessoas que praticaram delitos em conflitos considerados de caráter interno, que até então não se enquadravam na legislação penal internacional (13).

Na seqüência, resolveu-se instituir uma corte criminal permanente, para evitar a seletividade representada pela instituição de tribunais ad hoc, que dependem de decisão do Conselho de Segurança da ONU, no qual cinco potências têm o poder de veto. Essa seletividade impediu, por exemplo, a investigação e a punição dos massacres perpetrados no Camboja, por Pol Pot, nos anos 1970, em que foram assassinadas mais de um milhão de pessoas (14). 

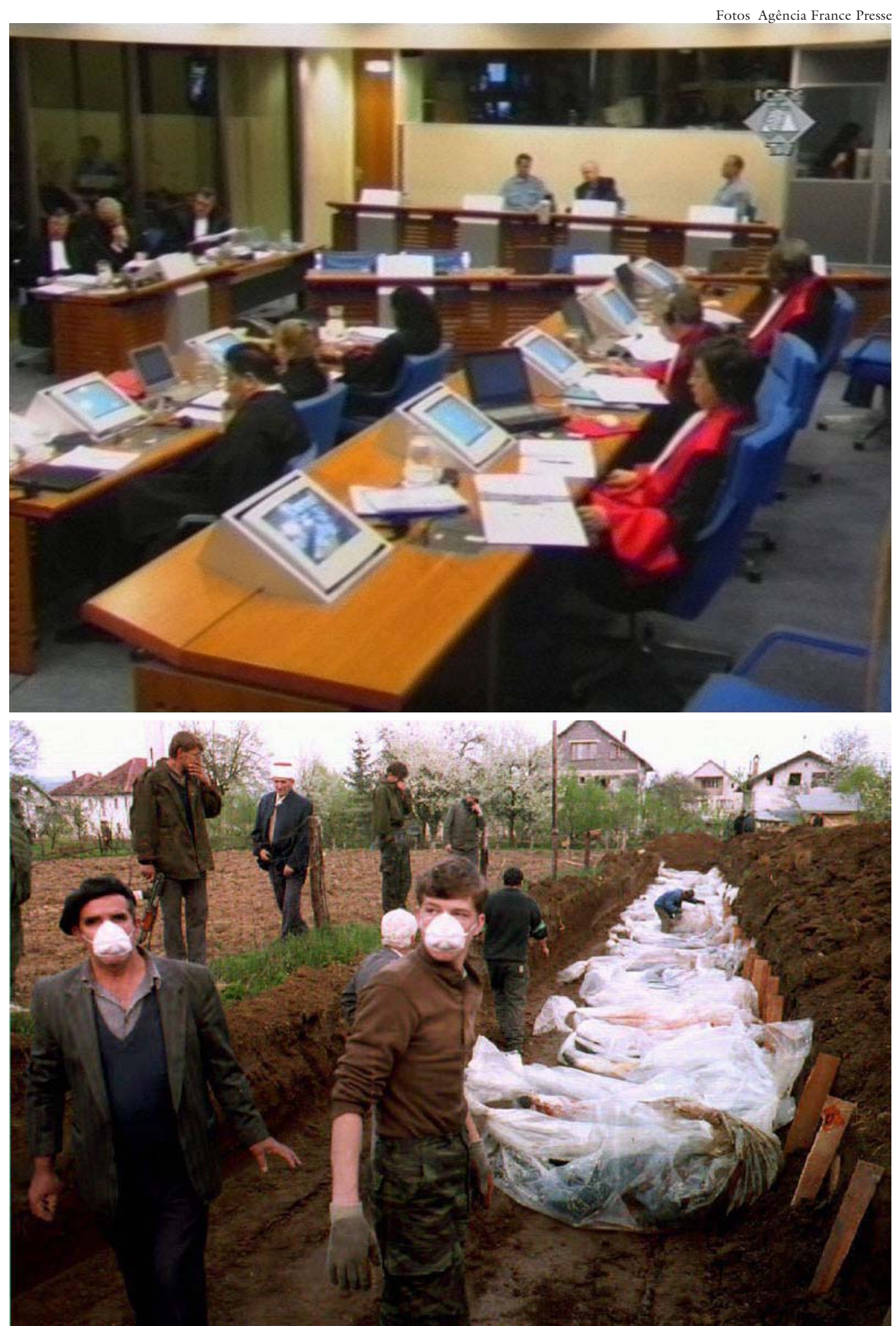

A experiência do Tribunal Penal Internacional para a antiga Ingoslávia, que levou ao banco dos réus o ex-presidente da Sérvia, Slobodan Milosevic, acusado de genocídio, durante a Guerra da Bósnia, mostrou a necessidade da criação de uma Corte Criminal Permanente, junto à $O N U$, para o julgamento de responsáveis pela prática de crimes contra a bumanidade. 


\section{Princípios fundamentais}

A atuação do Tribunal Penal Internacional assenta-se sobre alguns princípios fundamentais, sendo talvez o mais importante o da complementariedade. De acordo com o mesmo, a Corte somente atua se o Estado que tem jurisdição sobre determinado caso não iniciou o devido processo ou, se o fez, agiu com o intuito de subtrair o acusado à justiça ou de mitigar-lhe a sanção. Este postulado, à primeira vista, parece chocar-se com os fins colimados no Tratado de Roma, mas justifica-se porque compete em primeiro lugar aos Estados o dever de reprimir os crimes capitulados no Estatuto do Tribunal, até para que a repressão se faça de modo mais eficaz. A Corte, pois, atua apenas subsidiariamente, agindo sobretudo na hipótese em que ocorre "a falência das instituições nacionais" (15).

Outro é o princípio da universalidade, pelo qual os Estados-partes colocam-se integralmente sob a jurisdição da Corte, não podendo subtrair de sua apreciação determinados casos ou situações. O Estatuto contempla também o princípio da responsabilidade penal individual, segundo o qual o indivíduo responde pessoalmente por seus atos, sem prejuízo da responsabilidade do Estado. O princípio da irrelevância da função oficial, por sua vez, permite que sejam responsabilizados chefes de Estado ou de governo, ministros, parlamentares e outras autoridades, sem qualquer privilégio ou imunidade. Já o princípio da responsabilidade de comandantes e outros superiores exige que todos os chefes militares, mesmo que não estejam fisicamente presentes no local dos crimes, envidem todos os esforços ao seu alcance para evitá-los, sob pena de neles ficarem implicados. Por fim, o princípio da imprescritibilidade, de acordo com o qual a ação criminosa jamais terá extinta a punibilidade pelo decurso do tempo, embora ninguém possa ser julgado por delitos praticados antes da entrada em vigor do Tratado.

\section{Os crimes em espécie}

O Estatuto define o crime de genocídio como qualquer ato praticado "com intenção de destruir total ou parcialmente grupo nacional, étnico, racial ou religioso", compreendendo: (1) matar membros do grupo; (2) causar lesão grave à integridade física ou mental de membros do grupo; (3) submeter intencionalmente o grupo a condições de existência capaz de ocasionar-lhes a destruição física, total ou parcial; (4) adotar medidas destinadas a impedir nascimentos no seio do grupo; e (5) efetuar a transferência forçada de crianças do grupo para outro grupo.

Os crimes contra humanidade, qualificados como "qualquer ato praticado como parte de um ataque generalizado ou sistemático contra uma população civil e com conhecimento de tal ataque", incluem: (1) homicídio; (2) extermínio; (3) escravidão; (4) deportação ou transferência forçada de populações; (5) encarceramento ou privação grave da liberdade física em violação a normas fundamentais de direito internacional; (6) tortura; (7) estupro; (8) escravidão sexual, prostituição compulsória, gravidez imposta, esterilização forçada ou outros abusos sexuais graves; (9) perseguição de um grupo ou coletividade com identidade 
própria, por motivos políticos, raciais, nacionais, étnicos, culturais ou religiosos; (10) desaparecimento de pessoas; (11) apartheid; e (12) outras práticas que causem grande sofrimento ou atentem contra a integridade física ou saúde mental das pessoas.

São crimes de guerra os praticados em conflitos armados de índole internacional ou não, em particular quando cometidos como parte de um plano ou política para cometê-los em grande escala, abrangendo violações graves das Convenções de Genebra de 1949 e demais leis e costumes aplicáveis aos conflitos armados, especialmente: (1) homicídio doloso; (2) tortura e outros tratamentos desumanos; (3) ataque a civis e destruição injustificada de seus bens; (4) tomada de reféns; (5) guerra sem quartel; (6) saques; (7) morte ou ferimento de adversários que se renderam; (8) utilização de veneno e de armas envenenadas; (9) manejo de gases asfixiantes ou armas tóxicas; (10) uso de armas, projéteis, materiais ou métodos que causem danos supérfluos ou sofrimentos desnecessários; (11) emprego de escudos humanos; (12) morte de civis por inanição; (13) organização de tribunais de exceção; e (14) recrutamento de crianças menores de 15 anos.

O crime de agressão, depois de muita discussão, acabou sendo inserido no Estatuto, mas não foi definido, pelo que não pode ser aplicado, diante da exigência de estrita tipificação das figuras delituosas que vigora no campo penal. Esse delito poderá ser mais tarde incluído na jurisdição do Tribunal, se for devidamente caracterizado por ocasião da reforma do Estatuto, que ocorrerá dentro de sete anos depois de sua entrada em vigor. Deverá, no entanto, amoldar-se à Carta das Nações Unidas, que prevê algumas hipóteses de guerra justa, a exemplo da intervenção para prevenir ou reprimir ameaças à paz.

\section{Composição da Corte}

O Tribunal será integrado por 18 juízes, no mínimo, que se distribuirão por três Seções: a Seção de Questões Preliminares, incumbida de examinar a admissibilidade dos processos, a Seção de Primeira Instância, que proferirá os julgamentos, e a Seção de Apelações, responsável pela apreciação dos recursos.

A escolha dos juízes caberá à Assembléia dos Estados-partes, recaindo sobre pessoas que gozem de elevada consideração moral, imparcialidade e integridade, e que possuam as condições exigidas para o exercício das mais altas funções judiciárias de seu país, além dominarem uma das línguas oficiais da Corte (inglês, francês, espanhol, russo e árabe). Devem ainda apresentar: (1) reconhecida competência em direito penal e processual penal, e também experiência como juiz, promotor ou advogado; ou, alternativamente, (2) reconhecida competência no campo do direito internacional humanitário e direito internacional dos direitos humanos, assim como experiência nas funções jurídicas relacionadas com o Tribunal. Na seleção dos magistrados, a Assembléia deverá atentar para que exista equilíbrio entre candidatos que apresentem uma dessas duas qualificações. Exige-se também que estejam representados os principais sistemas jurídicos do mundo 
e que haja uma presença geográfica eqüitativa, assim como uma participação balanceada de homens e mulheres.

A Promotoria integra a Corte como um órgão independente do Tribunal, sendo dirigida por um promotor-chefe, coadjuvado por mais um promotor adjunto, no mínimo, escolhidos pela Assembléia dos Estados-partes para um mandato de nove anos, dentre pessoas da mais alta idoneidade, experientes na tarefa da persecução penal e que também dominem pelo menos uma das línguas oficiais do Tribunal.

\section{Mecânica processual}

Estão sujeitos à jurisdição do Tribunal os Estados-partes e os respectivos nacionais, assim como todos aqueles que se encontrem em seu território ou em navios e aviões que estejam sob sua bandeira. Também se incluem entre os jurisdicionados da Corte os Estados que submeterem à mesma algum caso específico, ainda que não tenham aderido ao Tratado.

O procedimento acusatório pode iniciar-se por uma representação à Promotoria, subscrita por algum Estado-parte ou pelo Conselho de Segurança da ONU, ao abrigo do Capítulo VII da Carta das Nações Unidas, ou ainda por uma investigação aberta pelo próprio Parquet (16). O processo perante o Tribunal, todavia, somente começa se for admitido pela Seção de Questões Preliminares, à vista de indícios suficientes de culpabilidade do acusado apresentados pela Promotoria. Essa Seção poderá também ordenar a prisão preventiva do acusado, para assegurar seu comparecimento em juízo, para que ele não obstrua a investigação, destruindo provas ou ameaçando testemunhas, ou mesmo para impedir que prossiga cometendo crimes. Essa prisão será executada pelos Estados-partes ou por terceiros mediante os instrumentos de cooperação internacional.

\section{Penas aplicáveis}

Uma vez considerado culpado, o réu estará sujeito às seguintes penas: (1) reclusão pelo prazo não superior a trinta anos; $(2)$ prisão perpétua, dependendo da gravidade do delito cometido e das circunstâncias pessoais do acusado; (3) multa; e (4) confisco de bens procedentes direta ou indiretamente da prática do crime. A pena será cumprida em um dos Estados-partes e poderá ser reduzida depois do cumprimento de um terço ou de 25 anos, no caso de prisão perpétua, atentando-se para a colaboração prestada pelo réu durante o julgamento.

O Tribunal poderá também fixar uma reparação às vítimas, sob a forma de reabilitação ou indenização, que será paga pelo réu ou por um Fundo Fiduciário, especialmente criado para esse fim, constituído por bens confiscados e por contribuições dos Estados-partes.

\section{Impunidade versus responsabilidade}

Embora uma parcela considerável da população mundial e grande parte do território do planeta tenham ficado fora da jurisdição do Tribunal, mais de dois 
terços dos Estados que integram a ONU subscreveram o Tratado de Roma, manifestando, assim, ainda que implicitamente, no caso daqueles que ainda não o ratificaram, a intenção de colaborar com a nova Corte. Nada impede, de resto, que aqueles que não aderiram ao acordo o façam num momento posterior ou submetam, desde logo, certos casos à jurisdição do Tribunal, numa base ad hoc, como permite seu Estatuto.

Seja como for, a relevância histórica do Tratado não pode ser subestimada, pois a mera existência do Tribunal, como anotou Flávia Piovesan, em artigo recentemente publicado, terá o condão de limitar o darwinismo no campo das relações internacionais, onde prevalece a lei dos Estados mais fortes em face das nações mais débeis (17). Mas a maior contribuição que a nova Corte poderá dar para consolidar a paz, a segurança e o respeito aos direitos humanos no mundo será fazer com que ele transite de uma cultura de impunidade para uma cultura de responsabilidade (18).

\section{Notas}

1 Segundo o art. 49, I, da Constituição Federal, compete ao Congresso Nacional "resolver definitivamente sobre tratados, acordos ou atos internacionais que acarretem encargos ou compromissos gravosos ao patrimônio nacional”.

2 Sobre a soberania dos Estados nas organizações internacionais, veja Nestor Pedro Sagüés. El Estado soberano en el Pacto de la Sociedad de Las Naciones y en la Carta de la Organización de las Naciones Unidas (Buenos Aires: Asociación Argentina de Ex Becarios, 1976).

3 Cf. Nicolò Machiavelli. Il Principe e pagine di altre opere (Padova: Cedam, 1940), p. 120.

4 Cf. Jean Bodin. Les six livres de la République (Darmstadt: Scientia Aalen, 1961) [Facsímile da edição francesa de 1583, Liv. I, Chap.VIII, p. 122.]

5 Cf. Thomas Hobbes. Leviathan: or the matter, forme, and power of a Commonwealth ecclesiasticall and civil (Londres: Collier, MacMillan, s.d.), p. 132.

6 Cf. Jacques-Benigne Bossuet, Politics drawn from the very words of Holy Scripture (Cambridge: Cambridge University Press, 1999), pp. 81/101.

7 Sobre a matéria, veja Sérgio Pistone; "Razão de Estado" em Norberto Bobbio et alii. Dicionário de politica, vol. 2 (Brasília: UNB, 1991).

8 Sobre os armamentos e o morticínio da Primeira Guerra Mundial, consulte John Keegan. Uma história da Guerra (São Paulo: Companhia das Letras, 1995), pp. 37077.

9 Cf. A. W. Palmer. "Treaty of Versailles", A dictionary of modern history: 1789-1945, (Harmonsdworth: Penguin, 1975). Lembra-se que o Imperador Guilherme II obteve asilo na Holanda, que se recusou a extraditá-lo para julgamento.

10 Sobre as cláusulas do tratado, veja R.R. Palmer e Joel Colton. A history of the modern world, $7^{\text {a }}$ edição (Nova York: Mc-Graw Hill, 1992), pp. 723-27. 
11 Cf. William Woodruff. A concise history of the modern world: 1500 to the present (Houndmills: Macmillan, 1992), p. 141.

12 Cf. Louis Henkin et alii. International law: cases and materials (St. Paul: West Publishing, 1980), pp. 906-7.

13 Sobre o tema, veja Ian D. Seiderman. Hierarchy in international law: the human rights dimension (Antuérpia: Intersentia, 2001), pp. 23-5.

14 Cf. Peter Calvoressi. World politics since 1945, $7^{\text {a }}$ edição (Londres: Longman, 1996), p. 528.

15 Cf. Francisco Rezek, "Tribunal Penal Internacional: Princípio da Complementariedade e Soberania" em Revista do Centro de Estudos Judiciários do Conselho da Justiça Federal, $\mathrm{n}^{\circ} 11$ (Brasília: agosto de 2000).

16 Veja em Morten Bergsmo. "O Regime Jurisdicional da Corte Criminal Internacional" em Fauzi Hassan Choukr e Hai Ambos (orgs.) Tribunal Penal Internacional (São Paulo: Revista dos Tribunais, 2000), uma explicação da participação do CSN no processo, o qual observa que "é natural que o Conselho de Segurança, como órgão primário com responsabilidade pela manutenção da paz e da segurança internacionais, esteja apto para provocar situações junto à CIC, como consignado no Estatuto de Roma".

17 "A força do direito versus o direito da força”, Folha de São Paulo, 2 de maio de 2002.

18 "From a Culture of Impunity to Culture of Accountability": título de uma conferência acerca do tema realizada em Utrecht, na Holanda, sob os auspícios da ONU, de 26 a 28 de novembro de 2001 .

\section{Bibliografia}

BERGSMO, Morten. "O Regime Jurisdicional da Corte Criminal Internacional” em Fauzi Hassan Choukr e Hai Ambos (orgs.) Tribunal Penal Internacional (São Paulo: Revista dos Tribunais, 2000).

BODIN, Jean. Les six livres de la République (Darmstadt: Scientia Aalen, 1961) [Facsímile da edição francesa de 1583].

BOSSUET, Jacques-Benigne Bossuet. Politics drawn from the very words of Holy Scripture (Cambridge: Cambridge University Press, 1999).

CALVORESSI, Peter. World politics since 1945, $7^{\text {a }}$ edição (Londres: Longman, 1996).

HENKIN, Louis et alii. International law: cases and materials (St. Paul: West Publishing, 1980).

HOBBES, Thomas. Leviathan: or the matter, forme, and power of a Commonwealth ecclesiasticall and Civil (Londres: Collier, MacMillan, s.d.).

KEEGAN, John. Uma história da Guerra (São Paulo: Companhia das Letras, 1995).

MACHIAVELLI, Nicolò. Il Principe e pagine de altre opere (Pádua: Cedam, 1940).

PISTONE, Sérgio. "Razão de Estado" em Norberto Bobbio et alii. Dicionário de política, vol. 2 (Brasília: UNB, 1991). 
PALMER, A . W. "Treaty of Versailles” em A dictionary of modern history: 1789-1945 (Harmonsdworth: Penguin, 1975).

PALMER R.R. e Joel Colton. A history of the modern world, $7^{\text {a }}$ edição (Nova York: McGraw Hill, 1992).

PIOVESAN, Flávia. "A Força do Direito versus o Direito da Força”, Folha de São Paulo, 2 de maio de 2002.

RESEK, Francisco. "Tribunal Penal Internacional: Princípio da Complementariedade e Soberania", Revista do Centro de Estudos Judiciários do Conselho da Justiça Federal, $\mathrm{n}^{\circ}$ 11 (Brasília: agosto de 2000).

SAGÜÉS, Nestor Pedro Sagüés. El estado soberano en el pacto de la Sociedad de las Naciones y en la Carta de la Organización de las Naciones Unidas (Buenos Aires: Asociación Argentina de Ex Becarios, 1976).

SEIDERMAN, Ian D. Hierarchy in international law: the human rights dimension (Antuérpia: Intersentia, 2001).

WOODRUFF, William. A concise history of the modern world: 1500 to the present (Houndmills: Macmillan, 1992).

Enrique Ricardo Lewandowski é desembargador do Tribunal de Justiça de São Paulo e professor da Faculdade de Direito da USP.

Conferência do Mês do Instituto de Estudos Avançados da USP feita pelo autor em 4 de junho de 2002. 